\title{
Microsatellite analysis of the mating system of Bruguiera gymnorrhiza and Kandelia obovata
}

\author{
Mohammad Basyuni ${ }^{1,2, *}$, Shigeyuki $\mathrm{Baba}^{3}$, Hirosuke $\mathrm{Oku}^{4}$, Ridha Wati ${ }^{1,2}$, and Annisa Fitri ${ }^{1,2}$ \\ ${ }^{1}$ Universitas Sumatera Utara, Department of Forestry, Faculty of Forestry, Jl. Tri Dharma Ujung No. 1 Medan, North Sumatera 20155 , \\ Indonesia \\ ${ }^{2}$ Universitas Sumatera Utara, Mangrove and Bio-Resources Group, Center of Excellence for Natural Resources Based Technology, \\ Medan North Sumatera 20155, Indonesia \\ ${ }^{3}$ University of the Ryukyus, International Society for Mangrove Ecosystems, Faculty of Agriculture, 1 Senbaru, Nishihara, Okinawa 903- \\ 0213, Japan \\ ${ }^{4}$ University of the Ryukyus, Molecular Biotechnology Group, Tropical Biosphere Research Center, 1 Senbaru, Nishihara, Okinawa $903-$ \\ 0213, Japan
}

\begin{abstract}
Microsatellite loci were used for estimating mating system for three populations of $B$. gymnorrhiza and K. obovata (Rhizophoracea) in Okinawa, Japan. Mother trees and thirty offspring of individual samples representing the population of both species were genotyped at five microsatellites. The mating system was examined using two approaches: a mixed mating model of multilocus testing, implemented by MLTR program and outcrossing rate from the level of inbreeding. Mating system analysis showed multilocus outcrossing rates $(\mathrm{tm})$ for both species was $0.850-1.000$ and $0.780-0.938$ respectively. By contrast, according to inbreeding level, tm was lower than MLRT: $0.495-1.028$ and $0.480-0.612$ of both species respectively. However, biparental inbreeding ( $\mathrm{tm}$ - ts) was diverse from zero both species for all three populations, showing that cross-fertilization events may ensue between the relatives both species. This data as well means the genetic relatedness (r) for B. gymnorrhiza and K. obovata were $0.108 \pm 0.025$ and $0.032 \pm 0.09$ respectively. Average relatedness was below 0.25 , the value for a half-sib relationship. These results suggest that postulation of a half-sib relationship among progeny of open-pollinated families is opposed for both mangrove tree species.
\end{abstract}

\section{Introduction}

Mangroves are typically tropical and sub-tropical coastal vegetation. However, they extend into subtropical environments in southernmost Japan. Natural mangrove forests mainly exist throughout the Ryukyu Archipelago, and they reach to Satuma Peninsular of Kyushu [1]. In Japan, ten mangrove species naturally distributed: Bruguiera gymnorrhiza, Kandelia candel, Rhizophora stylosa, Lumnitzera racemosa, Sonneratia alba, Avicennia marina, Heritiera littoralis, Nypa fruticans, Pemphis adicula, and Excoecaria agallocha, which three above mentioned of Rhizophoracea (B. gymnorrhiza, $K$. obovata, and $R$. stylosa) are relatively dominant $[1,2]$. The mangrove area at Okukubi River mouth and Katabaru River, Okinawa are colonized by four principal species: B. gymnorrhiza, K. obovata, $R$. stylosa, and $L$. racemosa. B. gymnorrhiza is denser in population, growing taller, and preferring to grow under dark conditions, while $K$. obovata and $R$. stylosa require more sunlight $[2,3]$.

One of the critical characterizations of mangroves, particularly Rhizophoracea is the production of viviparous offspring. Their seeds develop into seedling while they are still attributed to the mother tree. In viviparous mangrove species, the embryo ruptures the pericarp, grows beyond it before dispersals such as $B$. gymnorrhiza, $K$. obovata and many other species of Rhizophoracea $[4,5]$. However, the influence of this important dispersal mechanism on the mating system is not much concerned.

Furthermore the level of gene flow through seed dispersal and mating system of a species also play an essential role in responsible to population genetic structure. Even though the mating system of mangrove species may be implied from their reproductive appearance, molecular markers especially microsatellite may provide more precise information on the actual level of outcrossing rate in diverse populations. Several studies have shown the chlorophyll-deficient heterozygotes of offspring to evaluate outcrossing rate in natural populations of $R$. mangle [6] and K. obovata [7]. Allozyme loci were used to assess a mating system of $K$. obovata [8], B. gymnorrhiza [9]. Microsatellite markerbased multilocus estimates of mating system parameters have been used for mangrove species, such as Avicennia germinans [10,11] and B. gymnorrhiza [12].

The restricted mangroves area in Japan, therefore the preservation and management resources to be an urgent issue. Reliable information on the distribution of

\footnotetext{
Corresponding author: m.basyuni@usu.ac.id
} 
population genetic structure and mating system of mangrove tree species is essential to establish an active network of conservation populations [13]. In conservation programmes for a mangrove species, there is also requirement to detect close relatives to evade consanguineous mating and to diminish venomous concerns of inbreeding and the forfeiture of genetic diversity. Moreover, pairwise measures of gene relatedness also play a role in the field of conservation genetics and tree improvement programs. Information on the genetic relatedness among family members is indispensable for effective genetic range and estimate of genetic improvements in artificial selection schemes $[14,15]$.

Therefore, the present objective study was to investigate two mangrove species, B. gymnorrhiza and $K$. obovata (Rhizophoraceae), concerning its mating system and genetic relatedness using microsatellite markers. Information on mating system factors will not only clarify the profile of population genetic structure but also contribute to the conservation, management, and mangrove tree genetic resources utilization.

\section{Materials and methods}

\subsection{Study site and sample collection}

This work site was done in Okukubi River and Katabaru River, Okinawa, Japan as depicted in Fig. 1. For estimating outcrossing rates, three trees of $B$. gymnorrhiza and three trees of $K$. obovata as mother tree family arrays were sampled, where containg plentiful propagules still attributed to trees at the time sampling. 30 propagules per tree as materials for progeny arrays obtained in mating system obervation. Meanwhile, 30 propagules each species representing as population namely Okukubi left the side, Okukubi right the side, and Katabaru were also collected for studying mating system and genetic relatedness (Table 1). The propagules were directly obtained from the study site during the fruit season. Collected samples were maintened at $-30{ }^{\circ} \mathrm{C}$ until required for DNA extraction.

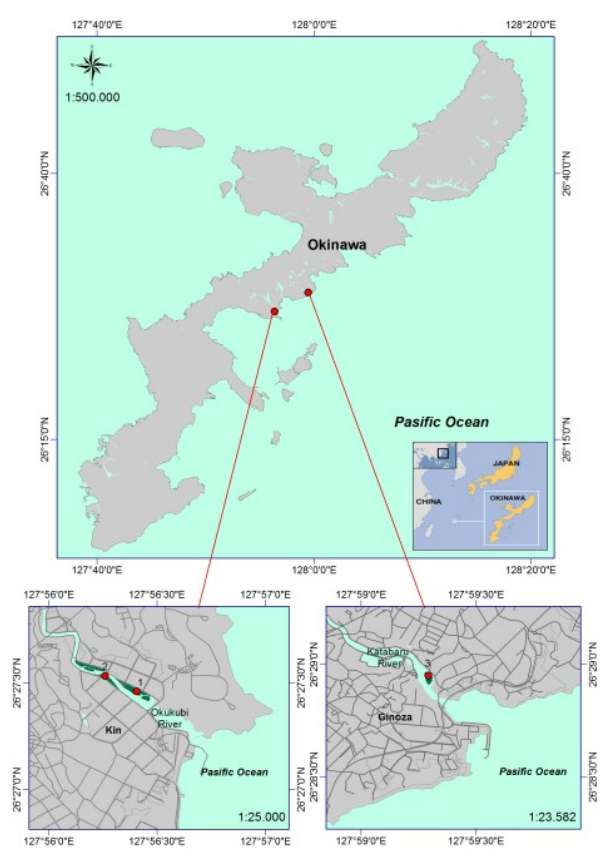

Fig 1. Study site for samples collection

\subsection{DNA extraction and microsatellite analysis}

Total DNA is isolated from young leaves of mother tree arrays and propagules as progeny arrays using modified CTAB procedure [16]. Five primer pairs, MSBgy025, MSBgy027, MSBgy030, MSBgy031 and MSBgy188 [17] were used in B. gymnorrhiza as well as five primer pairs (Kcan004, Kcan005, Kcan009, Kcan011, and Kcan034) of K. obovata according to Sugaya et al. [18]. PCR condition mixtures $(10 \mu \mathrm{l})$ composed of $10 \mathrm{X} \mathrm{Ex}$ Taq buffer, $1.5 \mathrm{mM} \mathrm{MgCl} 2,0.2 \mathrm{mM}$ of each dNTP, 0.1 $\mu \mathrm{M}$ of each primer (fluorescent forward and reverse), 10 ng template DNA and 1.0 U of Taq polymerase. PCR program was performed for $3 \mathrm{~min}$ at $94{ }^{\circ} \mathrm{C}$ for, followed by 35 cycles of $1 \mathrm{~min}$ at $94{ }^{\circ} \mathrm{C}, 30 \mathrm{~s}$ at the optimum annealing temperature and $30 \mathrm{~s} 72{ }^{\circ} \mathrm{C}$, with the final extension of $5 \mathrm{~min}$ at $72{ }^{\circ} \mathrm{C}$ using a PCR System Model PC-806 (ASTEC). The PCR products were analyzed using an ABI PRISMR 310 Genetic Analyzer, genotypes were driven by GeneScan and ABI PRISM Genotyper software version 2.0. (Applied Biosystems).

Table 1. Characterization of 3 mother trees of B. gymnorrhiza and K. obovata.

\begin{tabular}{|l|l|c|c|c|}
\hline Name of species & Sites & Diameter (cm) & Height (m) & Stem form \\
\hline B. gymnorrhiza & Okukubi left side & 9 & 9 & straight \\
\hline & Okukubi right side & 10 & 10 & straight \\
\hline & Katabaru & 9 & 8 & straight \\
\hline K. obovata & Okukubi left side & 8 & 7 & straight \\
\hline & Okukubi right side & 8 & 6 & straight \\
\hline & Katabaru & 7 & 10 & straight \\
\hline
\end{tabular}




\subsection{Data Analysis}

\subsubsection{Mating system}

To assess single- and multilocus outcrossing rates (probability that each offspring of a maternal plant is an outcross) was performed using two ways: the outcrossing rate from inbreeding coefficient as: 1FIS/1+FIS [19], and under the mixed mating model of Ritland [20], carried out by MLTR software [20].

As the maternal genotypes were recognized, the subsequent inbreeding considerations were measured for each population: multilocus (tm) and single-locus (ts) outcrossing rate; mean single-locus inbreeding coefficient of maternal parents (f), the correlation of outcrossing rate inside progeny arrays (rt), and the association of outcrossed paternity within progeny or the correlation of paternity (rp). The expectationmaximization method was done for maximaze the likelihood calculation to assess all parameters and correlations, and 100 bootstraps were carried out, and standard errors were acquired for every parameter [20].

\subsubsection{Genetic relatedness}

Genetic relatedness (r) according to Queller and Goodnight [21] within all individuals (progeny) of each species based on microsatellite genotypes was calculated using FSTAT version 2.9.3 [22]. Means and standard deviation for genetic relatedness were obtained by jackknifing over all loci in FSAT version 2.9.3.

\section{Results and discussion}

\subsection{Mating system}

In all progeny groups, all sibs shown at one of the maternal alleles, clarifying Mendelian inheritance and suggestive of no propagule impurity. Based on MLTR, single-locus outcrossing rate (ts) for B. gymnorrhiza and $K$. obovata were $0.848-0.995$ and $0.600-0.760$, while multilocus outcrossing rates (tm) was $0.850-1.000$ and 0.780-0.938 correspondingly (Table 1). In $B$. gymnorrhiza Katabaru population had the highest tm (1.000) (complete outcrossing rate) and ts (0.995). Meanwhile, for $K$. obovata of Okukubi left side population possessed the highest value of tm (0.938) and ts $(0.760)$ (Table 2$)$.

However, according to level inbreeding, multilocus outcrossing rates (tm) was 0.495-1.028 (complete outcrossing rate) and 0.480-0.612 respectively (Table 4). Nonetheless, biparental inbreeding (tm- ts) was diverse from zero both species for all three populations, signifying that outcrossing measures may happen between relatives.

The parental inbreeding coefficient (f) was significantly different for both species all populations except in Okukubi right (B. gymnorrhiza), where the density of generative individuals was subordinate (Table 2).

This study reports using deeply enlightening microsatellite markers to evaluate mating system parameters in mangrove tree species. Our results display that the high polymorphism of microsatellite markers provide determination to accurately differentiate selfing occurrences from outcrossing events, even between near relatives. Microsatellite markers evelove into more usually performed for this category of genetic analysis in mangrove trees, exceeding the popular isozymes. For instance, allozyme markers with a limited number of alleles; twisted allele frequencies and expected heterozygosities in the $20-30 \%$ extent may not support the necessity resolution to segregate such circumtance, notably, conditions [23].

The mating system has conventionally been associated by selfing or outcrossing rate, which effect profiles of population genetic structure. The high outcrossing rate estimate based on the mixed mating model of Multilocus Testing $\left(t_{\mathrm{m}}=0.850-1.000\right.$ with an average 0.946) for B. gymnorrhiza and $t_{\mathrm{m}}=0.780-0.938$ with an average 0.879 for $K$. obovata. Meanwhile, according to level inbreeding, multilocus outcrossing rates $\left(t_{\mathrm{m}}\right)$ was $0.495-1.028$ and $0.480-0.612$ respectively. $B$. gymnorrhiza was mixed-mating species, and its mating system was primarly outcrossing [9]. Kondo et al. [24] found that B. gymnorrhiza exclusively pollinated by birds and $R$. mucronata is wind pollination perhaps with some pollination by small insects. On the other hand, long-distance outcrossing and heterozygosity have favoured for B. gymnorrhiza, whereas short-distance outcrossing is favoured for $R$. mucronata.

Previous studies reported, based on proportion chlorophyll-deficient propagules on heterozygotes, the estimation of outcrossed rates ranged from 0.803 and 0.833 for two populations of $K$. obovata in Fujian. China [7]. On the contrary, using the same marker for chlorophyll-deficient propagules on heterozygotes showed that self-compatibility is very common in the population of $R$. mangle [25]. In Florida and San Salvador populations of $R$. mangle were characterized by high levels of selfing, $95.2 \%$ of the embryos separated from selfing; only $4.8 \%$ outcrossing happened [25]. Whereas, Puerto Rican $R$. mangle heterozygotes in which $71.2 \%$ of the embryos produced from selfing and $28.8 \%$ from outcrossing [6], indicating that inbreeding is a prevalent characteristic in $R$. mangle.

Besides, Sun et al. [8] observed the $t_{\mathrm{m}}$ was 0.679 and 0.797 in two K. obovata populations, Hongkong using allozyme marker. Whereas, using the same marker of isozyme, the outcrossing rates were estimated to be 0.267 to 0.845 with an average 0.623 in four populations of B. gymnorrhiza, China [9].

The large-flowered species of Bruguiera (e.g. B. gymnorrhiza) are well adapted to bird visitors. In $B$. gymnorrhiza the calyx is red, a colour attractive to birds, the flowers are directed outward, facilitation visits by an insect approaching the shoot [26]. Meanwhile, in $K$. obovata, was pollinated by a generalized population of flying insects [26].

\footnotetext{
*orresponding author: m.basyuni@usu.ac.id
} 
Tomlinson et al. [27] reported on the blooming biology of Rhizophoraceae species found a broad array of pollination mechanisms, containing wind pollination in Rhizophora, bird pollination in enormous-flowered and butterfly pollination in narrow-flowered of Bruguiera species, and moth pollination in some Ceriops species.

Moreover, the mating systems of entomophilous species are outcrossing. Outcrossing among and within populations of an entomophilous species can vary greatly [28]. Ecological and genetic factors also influenced the outcrossing rate such as mode of pollination, pollinator activity and adaptability, the architectural complexity of individual flowers and plants, the size and density of population, inbreeding incompatibility, etc. [28].

Outcrossing refers to the mating of genetically nonidentical individuals. In temperate and tropical trees, outcrossing levels have been highly characterized. Despite the outcrossing rate can vary from 0 (no outcrossing) to 1 (complete outcrossing), it also ranges from 0.60 to 1 in the tree species, and wide differences in rates take place among individuals yet of the same population. The intervals between trees and the timing of generative flowering (i.e., spatial and temporal variation) can also influence outcrossing levels [28].

This study showed that multilocus outcrossing rates predicted for these two mangrove tree species did not alter considerably from dominantly outcrossing and indicate that these species may be self-incompatible. This data is a correlation that a number of tropical species are genetically self-incompatible; that is, little or no seed is set succeding self-pollination [29].

However, biparental inbreeding $\left(t_{\mathrm{m}}-t_{\mathrm{s}}\right)$ was diverse from zero both species for all three populations. Biparental inbreeding as followed by the discrepancy $t_{\mathrm{m}}-$ $t_{\mathrm{s}}$ [20], was an order of magnitude higher than values using allozyme data [9]. The value of $t_{\mathrm{m}}-t_{\mathrm{s}}$ suggest that, even though the outcrossing rate was high, indicating that some cross-pollination apperances may happen between relatives. As important divergences were traced between $t_{\mathrm{m}}$ and $t_{\mathrm{s}}$, biparental inbreeding may be an essential parameter in both species (Table 2). This result is rather significant in substructured populations where arbitrary matings happen inside demes, and between firmly linked individuals [30].

Table 2. Estimates of the proportion of outcrossing for B. gymnorrhiza and K. obovata (standard errors in parentheses) using MLTR version 3.1

\begin{tabular}{|l|c|c|c|c|c|c|}
\hline Population & $\boldsymbol{t m}$ & $\boldsymbol{t}$ & $\boldsymbol{t} \mathbf{m}-\boldsymbol{t s}$ & $\boldsymbol{f}$ & $\boldsymbol{r t}$ & $\boldsymbol{r p}$ \\
\hline B. gymnorrhiza & & & & & & \\
Katabaru & $1.000(0.000)$ & $0.995(0.000)$ & $0.005(0.000)$ & $0.225(0.000)$ & $0.159(0.018)$ & $0.110(0.000)$ \\
Okukubi left & $0.850(0.001)$ & $0.848(0.026)$ & $0.002(0.025)$ & $0.080(0.000)$ & $0.195(0.000)$ & $0.098(0.002)$ \\
Okukubi right & $0.988(0.002)$ & $0.948(0.006)$ & $0.004(0.006)$ & $0.000(0.000)$ & $0.176(0.003)$ & $0.081(0.004)$ \\
& & & & & & \\
K. obovata & $0.780(0.113)$ & $0.600(0.110)$ & $0.180(0.028)$ & $0.040(0.001)$ & $0.033(0.047)$ & $0.022(0.099)$ \\
Katabaru & $0.938(0.028)$ & $0.760(0.209)$ & $0.178(0.207)$ & $0.410(0.000)$ & $0.135(0.000)$ & $0.100(0.029)$ \\
Okukubi left & $0.920(0.002)$ & $0.740(0.157)$ & $0.180(0.155)$ & $0.280(0.000)$ & $0.107(0.024)$ & $0.091(0.019)$ \\
Okukubi right & & & & & & \\
\hline
\end{tabular}

$t \mathrm{~m}$ : multilocus outcrossing rate, $t \mathrm{~s}$ : mean single-locus outcrossing rate, $f$ : parental inbreeding coefficient, $r \mathrm{t}$ : correlation of $t$ estimates, $r$ : correlation $p$ estimates.

Both rt (correlation of outcrossing rate within progeny groups) and $\mathrm{rp}$ (correlation of outcrossed paternity within offspring arrays) resulted in small values showing that outcrossing level was separate of progeny arrays and the likelihood of full-sibship in progeny arrays was shallow (Table 2).

\subsection{Genetic relatedness}

Genetic relatedness (r) was measured based on Queller, and Goodnight [21] and its standard deviation were estimated both species between all individuals. Mean genetic relatedness for $B$. gymnorrhiza and $K$. obovata were $0.108 \pm 0.025$ and $0.032 \pm 0.09$ respectively. Average relatedness was below 0.25 , the value for a half-sib relationship among progeny of open-pollinated families (Fig. 2) 

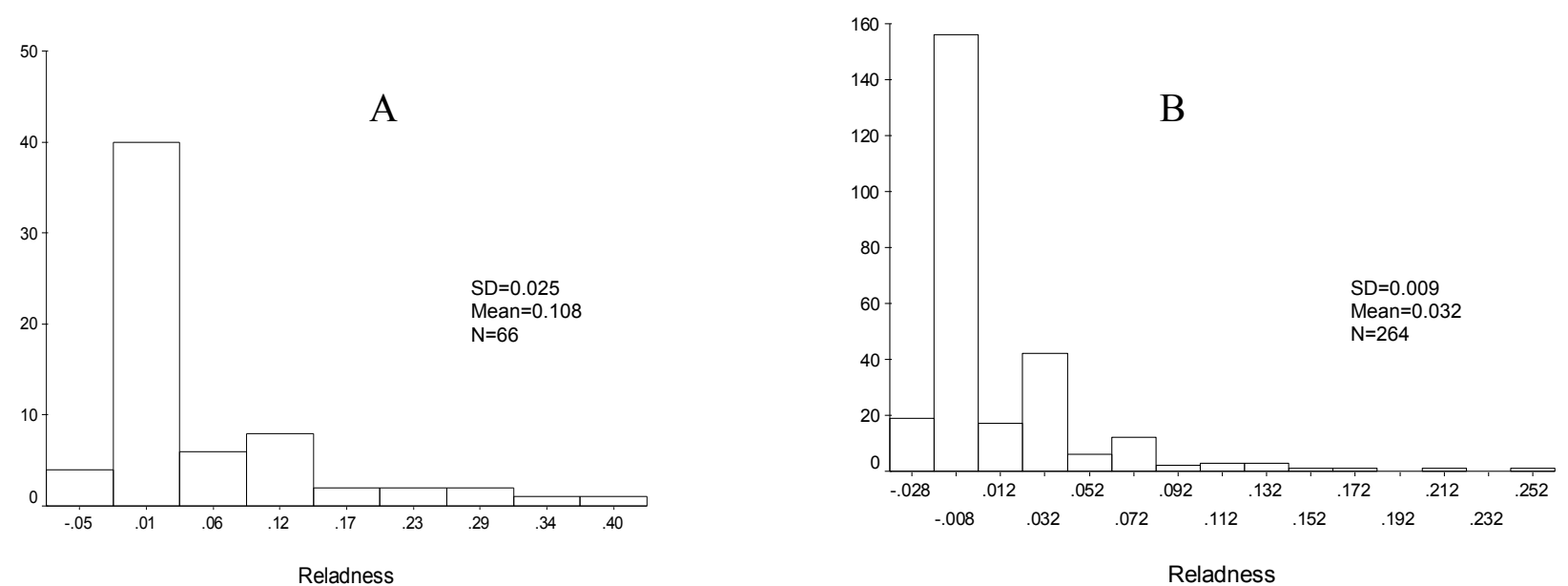

Fig 2. Distribution of genetic relatedness estimates ( $r$ ) among progeny for B. gymnorrhiza (A) and K. obovata (B).

The pattern of paternity is often neglected in plant mating system experiments. This parameter describes the genetic relatedness between individuals within the family. Genetic relatedness is often interpreted regarding numbers of individuals contributing genetically to the family formation, e.g. the number of reproducing females and the number of inseminations [31].

Both species showed the low value of genetic relatedness were $0.108 \pm 0.025$ and $0.032 \pm 0.09$ respectively. Average relatedness was below 0.25, the value for a half-sib relationship. In this circumstance, calculating additional genetic divergence and the heritability of character, geneticists frequently adopt a half-sib relation among progeny within open-pollinated families. This scenario is met entirely if every progeny is ascendant by a different male parent and if all male parents are uncorrelated. The genetic correlation or coefficient partnership on progeny, in this event, is 0.25 , showing that the progeny have $1 / 4$ of their genes in general [14].

Some characterizations of B. gymnorrhiza and $K$. obovata populations are of particular understanding to get more insight into genetic relatedness among progeny differs necessarily from the proposed half-sib level. Firstly, the genetic correlation among progeny may be enhanced by self-fertilization. However, the result of this study and from other populations of $K$. obovata $[7-8]$ and in B. gymnorrhiza $[9,26]$ indicate that outcrossing is a prevalent characteristic both species. Moreover, the overall values of $F_{\text {IS }}$ both species were 0.153 and 0.298 respectively, suggesting little to no breeding. The of inbreeding rate is decided not only by the nature of the reproductive system but also by family structure. The mating system itself is affected by pollen and seed dispersal typicals. Dispersal of pollen and seeds over a definite area can ehance the genetic relatedness of close individuals in a mating population and, by that, the promising of inbreeding [28].

Secondly, population sizes remain small. Because 20 of more effective fathers are needed for this condition $[14,32]$. Morever chances for inbreeding and enhanced relatedness value among progeny will be finely tuned if a number of individuals in these small populations are assocaited. Other factors that influenced the correlation value rely on allele frequency pattern at the loci used [33], individuals estimates of relatedness can be expected to be highly variable unless there is a great deal of genetic information for those individuals [21].

A part of this study was funded by an International Research Collaboration 2016-2018 from the Directorate for Research and Community Service, Ministry of Research, Technology and Higher Education, Republic of Indonesia.

\section{References}

1. M. Basyuni, H. Sagami, S. Baba, H. Iwasaki, H. Oku, Dendrobiology 75, 167-175 (2016).

2. K. Kathiresan, S. Baba, Seshaiyana 7, 3-6 (1999).

3. M. Basyuni, S. Baba, Y. Kinjo, L. A. P. Putri, L. Hakim and H. Oku, J. Plant Physiol. 169, 19031908 (2012).

4. M.Z. Hussain, Unasylva 181, 36-42 (1995).

5. T. Elmqvist, P.A. Cox, Oikos 77, 3-9 (1996).

6. E.J. Jr Klekowski, R. Lowenfeld, P.K. Hepler, Int. J. Plant Sci. 155, 373-381 (1994).

7. X.Y. Chen, Hydrobiologia 432, 189-193 (2000).

8. M. Sun, K. C. Wong, and J. S. Y. Lee, Am. J. Bot. 85, 161-1637 (1998).

9. J. Ge, B. Cai, and P. Lin, J Nat Sci 1, $42-48$ (2003).

10. A. Nettel-Hernanz, R.S. Dodd, M. Ochoa-Zavala, C. Tovilla-Hernandez, Bot. Sci. 9, 115-7 (2014).

11. G.M. Mori, M.I. Zucchi, I. Sampaio, A.P. Souza, Am J Bot 97, (2010).

12. M.S. Islam, C. Lian, N. Kameyama, T. Hogetsu, J. For. Res. 20, 293-300 (2015).

13. L. Graudal, E. Kjaer, A. Thomsen, A.B. Larsen, DFSC, Technical Note 48, 9-25 (1997).

14. S.E. Surles, J. Arnold, A. Schnabel, J.L. Hamrick, B.C. Bongarten, Theor. Appl. Genet. 80, 49-56 (1990)

15. M. Lynch, K. Ritland, Genetics 152, 1753-1766 (1999).

16. M. Basyuni, S. Baba, H. Oku, H IOP Conf. Ser.: Mater. Sci. Eng. 180, 012243 (2017).

17. T. Sugaya, H. Yoshimaru, T. Takeuchi, M. Katsuta, K. Fujimoto, S. Changtragoon, Mol. Ecol. Notes 3, 88-90 (2003).

\footnotetext{
* Corresponding author: m.basyuni@usu.ac.id
} 
18. T. Sugaya, T. Takeuchi, H. Yoshimaru, M. Katsuta, Mol. Ecol. Notes 2, 65-66 (2002).

19. B.S. Weir, Genetic data analysis II. (Sinauer, Sunderland, MA 1996).

20. K. Ritland, J Hered 88, 221-228 (2002).

21. D.C. Queller, K.F. Goodnight, J. Eval 43, 258-275 (1989).

22. J. Goudet, J Hered 86, 485-486 (1995).

23. R.G. Collevatti, D. Grattapaglia, J.D. Hay, J Hered 86, 60-67 (1999).

24. K. Kondo, T. Nakamura, K. Tsuruda, N. Saito, Y. Yaguchi, Biotropica 19, 377-380 (1987).

25. R. Lowenfeld, E.J. Klekewski Jr, Int. J. Plant Sci 153, 394-399 (1992).

26. P.B. Tomlinson, The Botany of Mangroves. (Cambridge University Press, Cambridge. 419pp, 1994).

27. P.B. Tomlinson, R. B. Primack, and J. S. Bunt, Biotropica 11, 256-277 (1979).

28. A.H.D. Brown, J.J. Byrdon, A.M. Jarosz, Isozyme Analysis of Plant Mating Systems. In Soltis, E.S. and P. S. Soltis (eds). Dioscorides Press, Portland, Oregon. 73-86 (1989).

K. S. Bawa, D. R. Perry, and J. H. Beach. Am J Bot 72, 331-345 (1985).

29. K.S. Bawa, J. Eval 28, 85-92 (1974).

30. K. Ritland, J. Eval 43, 848-859 (1989).

31. P. Pamelo, J Hered 103,195-200 (1985).

32. A.E. Squillace, Silvae Genet 23, 149-156 (1974).

33. M.S. Blouin, M. Parsons, V. Lacaille, and S. Lotz, Mol Ecol 5, 393-401 (1996). 